\title{
Software design of computer-aided ventilation and dust control system"
}

\author{
Xiu-Li Lin ${ }^{1, \text { a }, ~ Y a o-M a n ~ Z h a n g ~}{ }^{2, \mathrm{~b}}$, Guang-Xuan Liu ${ }^{1, \mathrm{c}}$ and Ya-Ping Cao ${ }^{1, \mathrm{~d}}$ \\ ${ }^{I}$ School of resources and Civil Engineering, Northeastern University, \\ Shenyang, 110819, China \\ ${ }^{2}$ School of mechanical Engineering \& Automation, Northeastern University, \\ Shenyang, 110819, China \\ ${ }^{a}$ E-mail:Linxiuli@mail.neu.edu.cn, ${ }^{b}$ E-mail: zhymlxl@163.com, \\ ${ }^{c}$ E-mail:505845488@qq.com, ${ }^{d}$ E-mail:853082074@qq.com
}

\begin{abstract}
The design of ventilation and dust control system has become the important part of environmental projects to provide a safe and health working condition for workers. A computer aided design software was developed based on ventilation and dust control theory using Visual Basic to help engineers to design ventilation system efficiently and conveniently. The software developed could help users to determine air flow rate, velocity, diameter of ducts, resistance of the system, fan, duct collector based on database of the software. The design project could be finished quickly following the design process in computer aided ventilation and dust control software which is effective and practicable.
\end{abstract}

Keywords: Computer-Aided Design; Ventilation And Dust Control System; Software Design; Occupational Safety And Health.

\section{Introduction}

Occupational safety and healthy have became an social focus problem in china. Ventilation is an efficient method to control dusts, toxic gases to protect employees from many kinks of occupational disease. The well designed ventilation and dust control system is important for the plant to improve its working environment, too.

Computer Aided Design(CAD) is widely used in the industrial design process, which can greatly improve the design efficiency and quality. It is a good way to program a computer aided design software using in ventilation and dust control system design, to help engineers design system rapidly, and effectively.

\footnotetext{
* This work was financially supported by the Fundamental Research Funds for the Central Universities (N140104001).
} 
Some ventilation design software such as Tianzheng HVAC(heating ventilation and air conditioning) series, Hongye company ACSV7.0 (8.0), and HaoChen technology development company INT6. 6, have been used in the design process in China[1-3]. But these software mostly focuses on HVAC system which did not think about the dust control process.

There are some good software for ventilation systems abroad, such as Excel 5000, Duct size 4.0(6.0) and so on[4-7].These software can not only design ducts, but also analysis duct systems. But they are not convenient for the user to design a ventilation and dust control system.

An new computer-aided ventilation and dust control system design software which include database of many kinds of fans and dust collectors and other data that design needed was developed based on Visual Basic(VB)program and ventilation theory to help engineers design the system efficiently, accurately and conveniently.

\section{Software Design of Computer Aided Ventilation and Dust control system}

\subsection{Programming language Selecting}

There are some common computer programming languages such as, $\mathrm{C}, \mathrm{C}++, \mathrm{VB}$, VF, JAVA, ASP, NET, JSP, etc. VB is short for Visual Basic, designed in 1991 by Microsoft. It is a visual, high-level structured programming language, based on object oriented and event driven. It's efficient and quick to develop software systems. VB was chose as programming language.

\subsection{Software designing of computer aided system}

The overall framework of the ventilation and dust control system design software is showed in Figure 1. The main functions that the design software contains air flow rate determination, draft designing, ducts designing, dust collector choosing, fan choosing, final design plan drawing and help. 


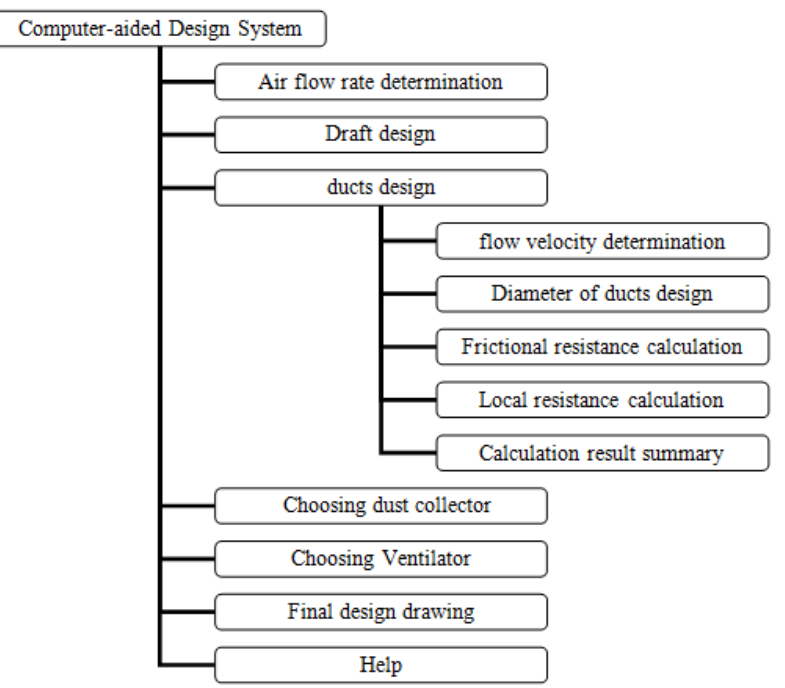

Fig. 1. The overall framework of the software

\subsection{Air flow rate determination}

It's very important to determine the air flow rate of the ventilation system accurately. Some kinds of equipments have reference exhaust air flow rate valves based on the model of the equipment, which can be obtained from handbooks. Data Collection work were done and exhaust air flow rate value of some crusher and grinding equipments, etc. were included in the software. Select the equipment and then the software can provide the air flow rate of exhaust of the equipment.

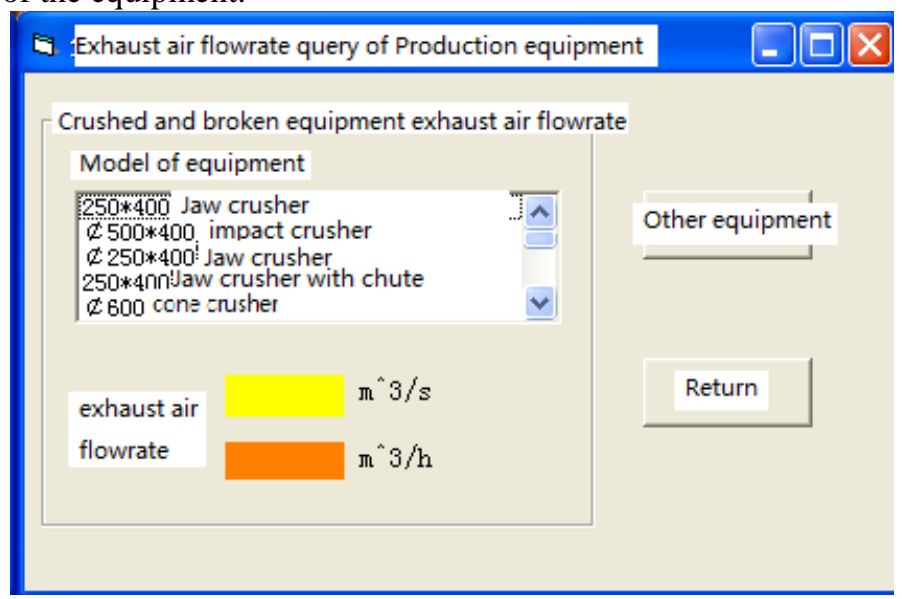

Fig. 2. Form of exhaust air flow rate selection. 


\subsection{Draft design}

The draft design could be designed by engineers after the system analysis. Using computer aided design software such as AutoCAD, the engineers can draw axonometric drawing wind network layout sketch, and mark the wind pipe, air flow rate of each pipe, length of pipes and the coefficient of local resistance and other important performance parameters.

\subsection{Ducts design}

Air velocity, diameter of ducts could be determined based on database of the designed software as shown in Figure 3. The velocity data of fiber dust, mineral dust, metal powder and other kinds of dust could be selected by using the software. Then the diameter of the duct could be determined by using the window of duct diameter calculation and selection, which is shown in Figure 4. Frictional resistance per meter, local resistance coefficient could be calculated and the resistance of the parallel duct could be compared and adjusted to balance. The final value could be collected in Figure 5 .

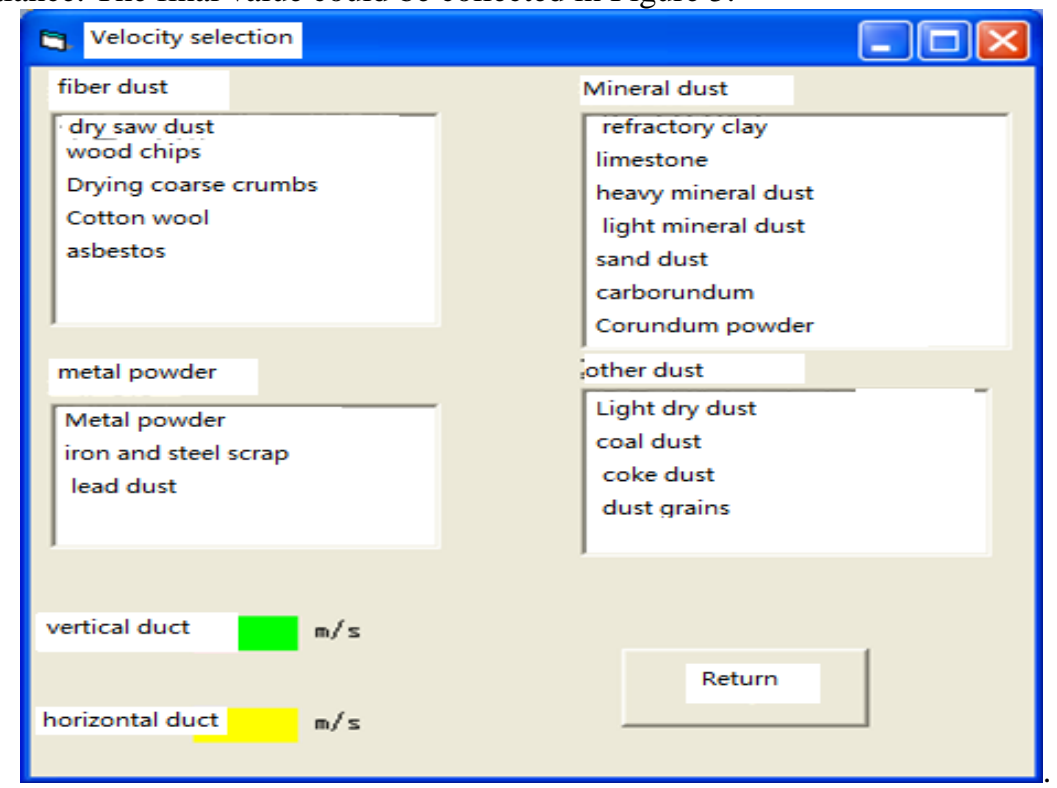

Fig. 3. Air velocity selection 


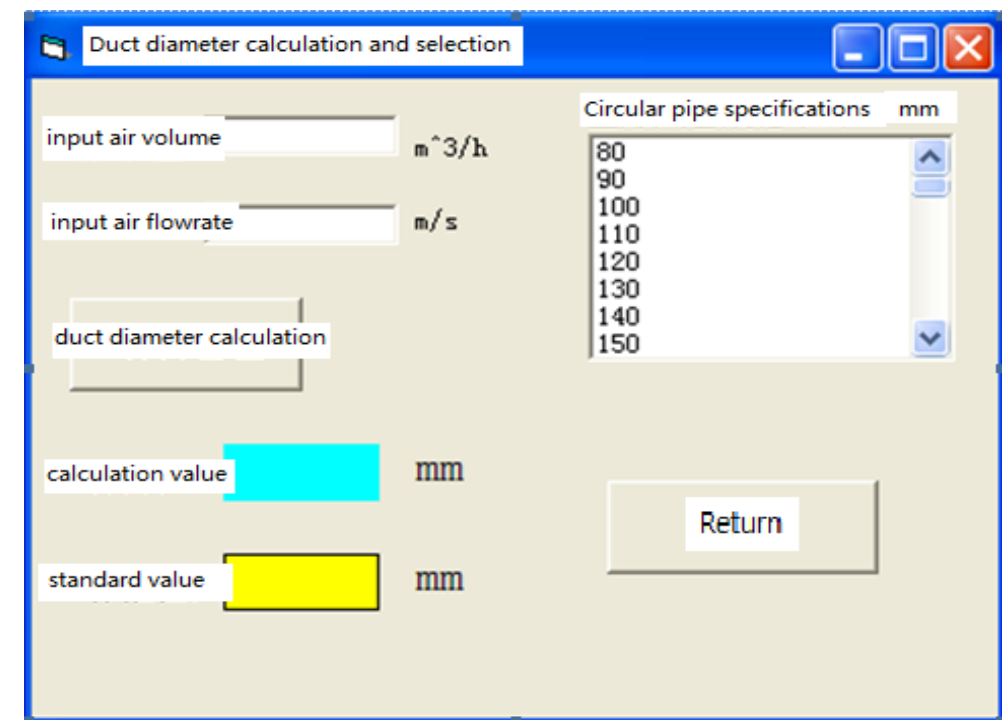

Fig. 4. Duct diameter calculation and selection

\subsection{Dust collector choosing}

Calculate the air volume and collection efficiency of the system, dust collector could be determined appropriately. Input dust concentration of the workshop, the concentration allowed to be discharged, and the air volume of the system, calculating by the software, the efficiency and the air flow rate of the dust collector could be determined. According to the database in the software an appropriate dust collector could be selected.

\subsection{Fan choosing}

Usually used fans were collected in database of ventilation and dust control design system. After Calculating the total air flow rate and pressure, engineers can choose the appropriate fan.

\subsection{Help model}

Help model provide assistance for users, including the steps of using the software and application examples for reference.

\section{Application of the Software}

The project including two cone crushers, which diameter is $2100 \mathrm{~mm}$, feeding from the conveyor belt, is used to crush limestone. The content of $\mathrm{SiO}_{2}$ in the 
broken limestone dust is lower than $<10 \%$. The dust concentration is $2600 \mathrm{mg} /$ $m^{3}$.the work shop room is 12 meters long, 8 meters wide, and 11 meters high.

Following the design steps, users can choose the dust collector after calculating dust collection efficiency, choose ventilator and then design the draft of the system.

The velocity, diameter, length can be determined following the design step using the software. The frictional resistance, the local resistance can be calculated under the help of the software. Then we can judge and adjust the balance of parallel resistance. The calculation form of the duct is showed in Figure 5.

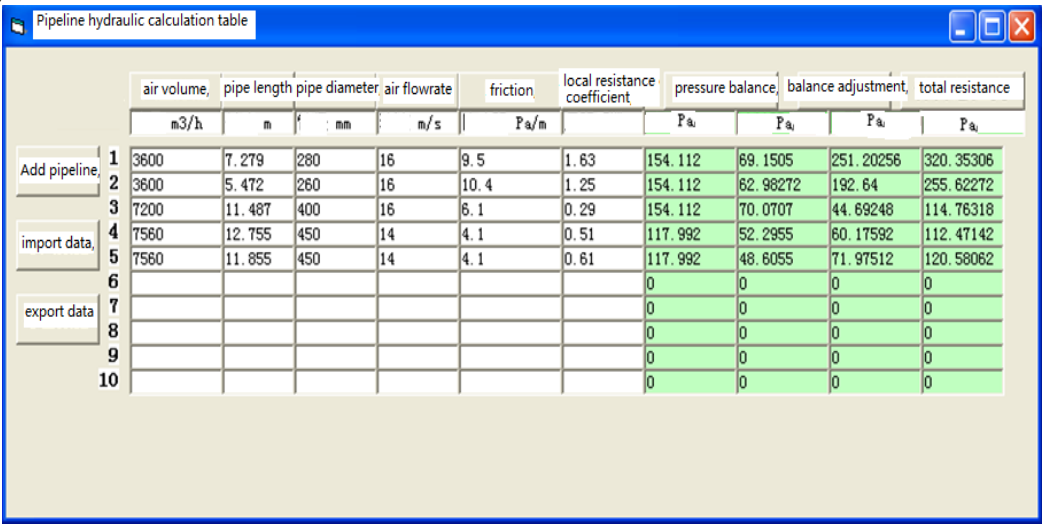

Fig. 5. Form of pipeline hydraulic calculation table.

Based on the design draft and the calculating results, formal drawing of the system can be done. A part of drawing is shown in Figure 6.

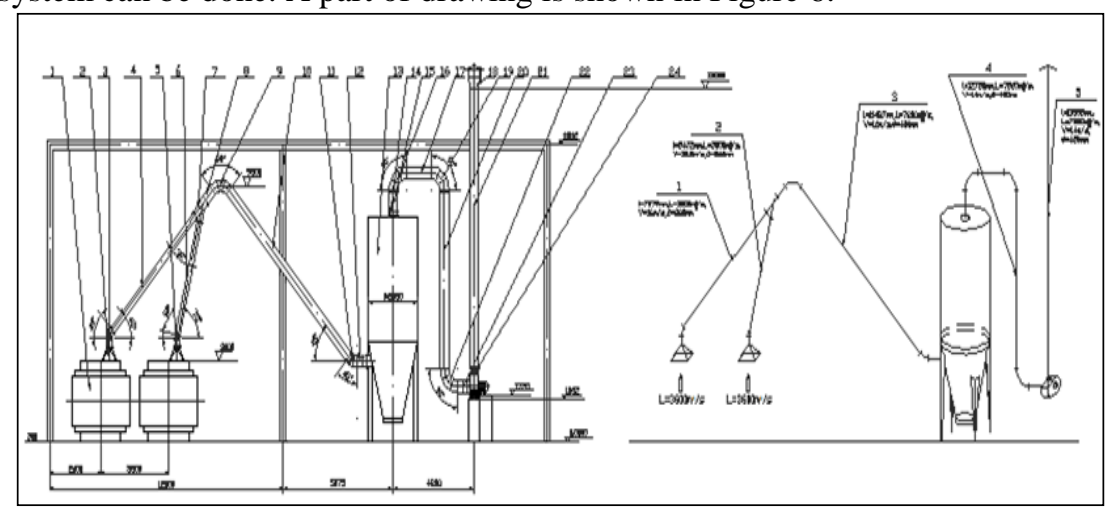

Fig. 6. Formal design drawing of the system. 


\section{Conclusions}

Based on theory of ventilation and dust control, a computer aided ventilation and dust control system design software was designed using VB. Database include many kinds of dust, dust producing equipment, dust collector, fan, duct diameter, local friction coefficient, etc. were established. The database could help users to choose the data needed directly. The ventilation and dust control system design, which include the calculation of ventilation ducts, the choice of dust collectors, and the choice of ventilators, could be easily finished by following the process of the software. The computer-aided design ventilation and dust control system software is effective and practicable when a case was used to give a practical application. It can provide a useful tool for the engineers who will design a local ventilation and dust control system.

\section{References}

1. Shougong Li, Zhan Zhao, etc. Research on the Intelligential CAD System for Air Conditioning, Building Science.14,56, (1998)(In Chinese)

2. Quanzhong Ren. Computer aided ventilation and dust control system design,ventilation and dust control. 14,39,(1994)(In Chinese)

3. Yushi Lu, Jianwen Jiang, Jing Yang. Network optimization design method of ventilation and dust control system, ventilation and dust control. 4,13,(1993)(In Chinese)

4. Roozbeh Ghaderi, Mohammed Javad Khoshharf. Building ventilation by wind, Building Integration Solutions. (2008).

5. Byung-Su Kim, Jae-chun Lee, Soo-Bock Jeong, ect. Kinetics of the Volatilization Removal of Zinc from Manganese Dust, Materials transactions. 7,51 (2010)

6. S. Rosanvallon, C. Grisolia, P. Delaporte, ect. Dust in ITER: Diagnostics and removal techniques, Journal of Nuclear Materials.386, (2009)

7. Antonio C. Caputo, Pacifico M. Pelagagge. Upgrading mixed ventilation systems in industrial conditioning, Applied thermal engineering. 14, 29, (2009). 